University of Montana

ScholarWorks at University of Montana

3-1998

\title{
Are Microhabitat Preferences of Coexisting Species Under Selection and Adaptive?
}

Thomas E. Martin

University of Montana - Missoula, tom.martin@umontana.edu

Follow this and additional works at: https://scholarworks.umt.edu/wildbio_pubs

Part of the Life Sciences Commons

Let us know how access to this document benefits you.

\section{Recommended Citation}

Martin, Thomas E., "Are Microhabitat Preferences of Coexisting Species Under Selection and Adaptive?"

(1998). Wildlife Biology Faculty Publications. 20.

https://scholarworks.umt.edu/wildbio_pubs/20

This Article is brought to you for free and open access by the Wildlife Biology at ScholarWorks at University of Montana. It has been accepted for inclusion in Wildlife Biology Faculty Publications by an authorized administrator of ScholarWorks at University of Montana. For more information, please contact scholarworks@mso.umt.edu. 


\title{
ARE MICROHABITAT PREFERENCES OF COEXISTING SPECIES UNDER SELECTION AND ADAPTIVE?
}

\author{
Thomas E. Martin \\ U.S. Biological Resources Division, Montana Cooperative Wildlife Research Unit, Avian Studies Program, \\ University of Montana, Missoula, Montana 59812 USA
}

\begin{abstract}
Microhabitat preferences are assumed to be adaptive, suggesting that fitness is higher in preferred microhabitats and potentially reflecting natural selection on habitat choices. I examined microhabitat preferences and adaptiveness of preferences for seven bird species coexisting in high elevation snowmelt drainages based on study of microhabitat and survival of 1556 nests. Habitat features in the nest patch differed from both random and non-use (sites centered on the same plant species as used for the nest) sites within each bird species, indicating nonrandom nest site choice. Bird species within a nesting guild (ground, shrub) also differed from each other based on the same vegetation features that differentiated nest sites from non-use and random sites, and this vegetation feature dominated the microhabitat type that was used most frequently by each species. In short, frequency of use of dominant vegetation types, comparisons of nest vs. random and nonuse sites, and comparisons among species were concordant in their indications of microhabitat preferences. The frequency in use of microhabitats was taken as an unambiguous measure of microhabitat preference within this study system: vegetation varied along a short microclimate gradient in the study system and territories of birds encompassed the entire gradient, thereby making all microhabitats available within the territory of each individual, such that use reflected a clear choice among alternatives. Microhabitat preferences differed among species and reflected differing positions on the microclimate gradient. Thus, species partitioned either microhabitat or microclimate within each nesting guild. Nest success was greater at preferred than at nonpreferred microhabitats for all seven species, indicating that preferences were adaptive. Examination of cubic spline curves and standardized directional selection differentials $(s)$ and selection gradients $(\beta)$ indicated that preferences had positive directional selection coefficients. These selection coefficients suggested that selection might be acting to favor preferences, but information on genetic bases of habitat choices is needed before selection can be ascertained. Advances in understanding evolution of habitat preferences depend on an individual-level examination of habitat choices and their fitness consequences, and also examination of the phenotypic traits and mechanisms that underlie habitat-induced variation in fitness components.
\end{abstract}

Key words: Arizona; directional selection; habitat preference; habitat selection; natural selection; nest predation; resource partitioning.

\section{INTRODUCTION}

Habitat preferences are assumed to be adaptive, such that fitness is higher in preferred habitats, causing natural selection to maintain preferences if they have a genetic basis (Jaenike and Holt 1991). Clear demonstration of adaptive habitat preferences, however, are uncommon. For example, some studies of the adaptiveness of host plant choice by insects have shown higher larval performance (a fitness component) on preferred hosts, but many other studies have shown lower or no change in performance (Thompson 1988, Jaenike and Holt 1991, Valladares and Lawton 1991, Etges 1993). Most of these tests with insects were conducted in laboratory environments where effects of enemies (i.e., predators and parasites) on fitness are understated. Tests in field situations where enemies are present may

Manuscript received 9 September 1996; revised 18 February 1997; accepted 2 April 1997. provide more appropriate tests of the adaptiveness of preferences, but such tests are rare and particularly so for vertebrates.

Studies of habitat preference in birds, for example, often do not examine fitness and instead measure density because density is expected to be positively correlated with habitat preference (Brown 1969, Fretwell 1972, Whitham 1980, Cody 1985, Petit and Petit 1996). However, density may not reflect preference or be positively correlated with fitness (van Horne 1983, Pulliam 1988). Fitness components need to be measured. Yet, when fitness is measured for birds, it is usually measured at the population level such that mean individual fitness is compared among habitats following Fretwell (1972). Such approaches ignore variation in fitness of individuals related to variation in microhabitat quality within habitats (Martin 1986). The clearest test of the adaptive basis of habitat preference is provided by examining the fitness consequences of habitat choices by 


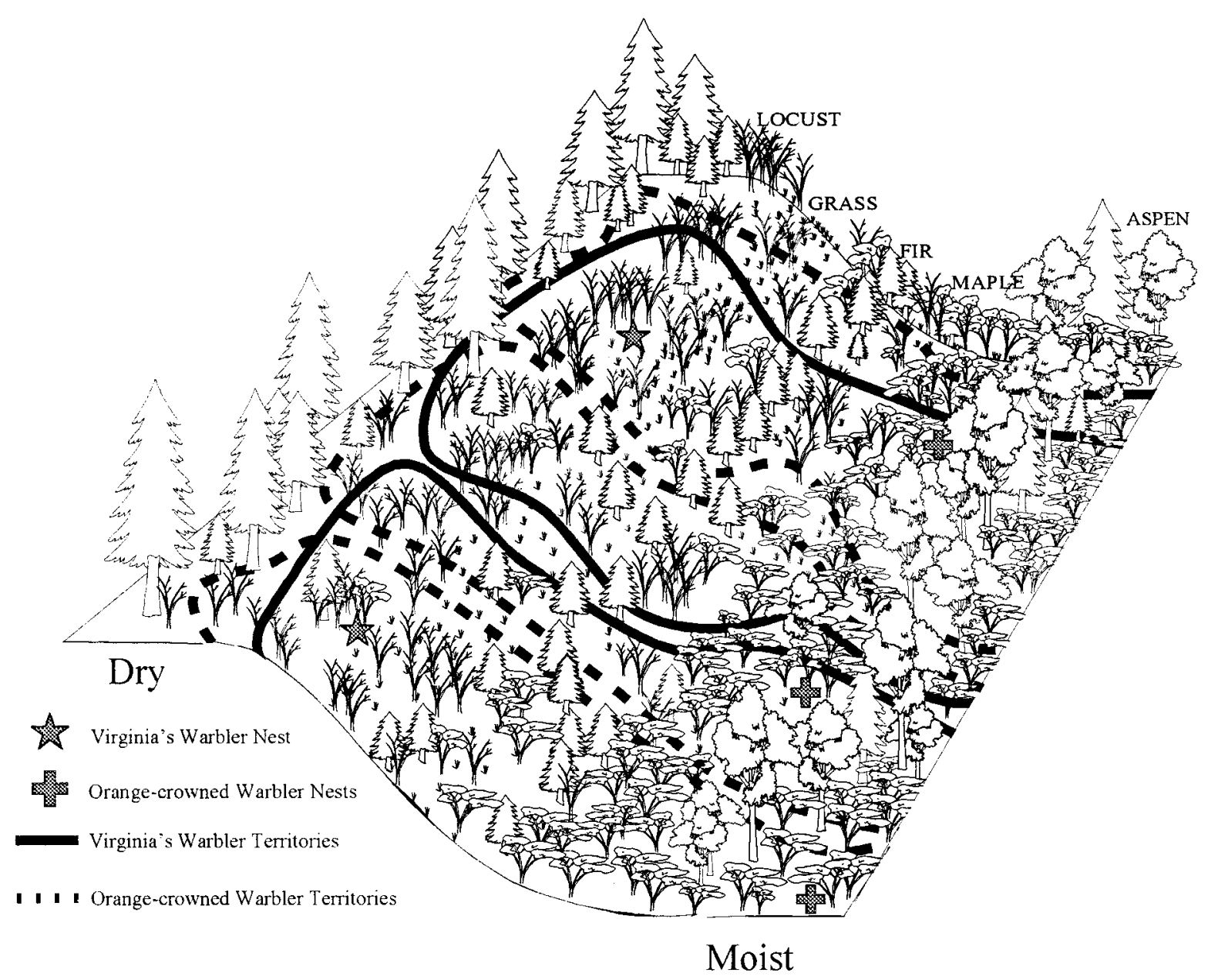

FIG. 1. Schematic representation of a half cross-section of a study site (snowmelt drainage; watercourse was at the righthand edge of the diagram). Sides of drainages were moisture gradients with plant species that varied along the gradient (see Results: Vegetation gradient). Sides of drainages were relatively short (35-75 m from top to bottom) such that territories of all individuals encompassed the entire gradient and species overlapped each other (personal observation). Bird species commonly differed in where they placed their nest along the gradient (see Results: Vegetation differences among random, non-use, and nest sites within species), but their territories still encompassed the entire gradient. Examples of territories and nest sites are provided for Orange-crowned Warblers and Virginia's Warblers, which typically nested at opposite ends of the gradient (Orange-crowned Warblers nested near the bottom, and Virginia's Warblers nested near the top), but had territories that completely included the entire gradient.

individuals when each individual is given the full range of habitats from which to choose.

Here, I examine nest site preferences and whether they are adaptive in a study system with seven groundand shrub-nesting bird species. I focus on nest site preferences because nest sites represent a readily quantifiable microhabitat that can have clear fitness consequences. Indeed, nest predation accounts for $98 \%$ of nest mortality in the study system (Martin 1992; T. E. Martin, unpublished data) and nest predation is influenced by microhabitat (Martin and Roper 1988, Martin 1993). The study system used here is particularly appropriate for examining microhabitat preferences because vegetation varies along a microclimate gradient and territories of each species encompassed the entire vegetation gradient (see Fig. 1), thereby making the complete range of potential nesting microhabitats available within the territory of each individual. Thus, I assume that the frequency that a microhabitat type is chosen represents preference, such that the most frequently chosen microhabitat is the preferred one for each bird species in this study system. I define microhabitats based on vegetation, but birds could have been choosing another environmental feature (e.g., microclimate) associated with plants. Yet, nests were generally placed under or in specific plants, suggesting that birds were choosing specific vegetation, and vegetation is known to directly influence nest survival (see Martin 1992, 1993). Thus, I assume that vegetation was a reasonable approximation of phenotypic variation in nest site choice and in influencing reproductive success. Selection can only act on this phenotypic variation if it 
has a genetic basis. Few data are available showing genetic bases of habitat selection, but I assume a genetic basis because some evidence suggested that habitat preferences do indeed have a genetic basis (see Jaenike and Holt 1991). Given that nest site choice can vary over time or with prior experience within individuals, then selection might be acting on a reaction norm. I begin by showing that nest site choices were nonrandom and differed among species. I then document preferences by examining the frequency of use of vegetation types. Subsequently, I examine adaptiveness of preferences and whether selection gradients could favor and maintain preferences.

\section{Study Area And Methods}

\section{Study area}

Study sites were 20 snowmelt drainages located on the Mogollon Rim in central Arizona at $\sim 2600 \mathrm{~m}$ elevation. Canopy trees were quaking aspen (Populus tremuloides), Douglas-fir (Pseudotsuga menziesii), white fir (Abies concolor), ponderosa pine (Pinus ponderosa, white pine (Pinus strobiformis), and Gambel's oak (Quercus gambellii). The understory included canyon maple (Acer grandidentatum), New Mexican locust (Robinia neomexicana), saplings of overstory tree species, golden pea (Thermopsis pinetorum), and various grasses. These drainages contrasted with surrounding forest, which was characterized by open ponderosa pine with Gambel's oak in the subcanopy and little understory vegetation.

The seven study species represented all species that nested on the ground or in shrubs in the understory on these sites: Virginia's Warbler (Vermivora virginiae), Dark-eyed Junco (Junco hyemalis), Red-faced Warbler (Cardellina rubifrons), Orange-crowned Warbler (Vermivora celata), Green-tailed Towhee (Pipilo chlorurus), MacGillivray's Warbler (Oporornis tolmei), and Hermit Thrush (Catharus guttatus).

Potential nest predators included Red squirrels (Tamiasciurus hudsonicus), gray-necked chipmunks (Eutamias cinereicollis), long-tailed weasels (Mustela frenata), House Wrens (Troglodytes aedon), and Steller's Jays (Cyanocitta stelleri). General observations on the sites and photographic records at artificial nests indicate that red squirrels and gray-necked chipmunks are the primary predators (Martin 1988, 1993).

\section{Field work}

Study drainages were searched for nests of all bird species from the beginning of May until the end of July from 1986 to 1995 . Nests were located by following adults, as described by Martin and Geupel (1993). I assume that this focus on parental behavior for finding nests minimized biases in microhabitat use that might arise from differences in detectability of nests if nests were sought by direct search. Date and status (nest building, presence of parents, eggs, or nestlings) of each nest was recorded every 3-4 days. Nests that fledged at least one young were considered successful. Observations of nestlings within $2 \mathrm{~d}$ of fledging age, fledglings near the nest, or parents feeding new fledglings in the general area of the nest were taken as evidence of a successful nest. Depredation was assumed when the nest or eggs or nestlings (when too young to fledge) disappeared. Most nests were found prior to onset of incubation, but some nests were not, and so daily survival and mortality rates were estimated following Mayfield (1975), Johnson (1979), and Hensler and Nichols (1981). Half the number of days between subsequent visits during which interval a nest was depredated was added to the number of previous days the nest survived, to obtain total exposure days observed. I lumped nests among years for purposes of this paper. Year effects existed in microhabitat preferences and are explored in more detail in another paper (T. E. Martin, unpublished manuscript). However, year effects did not change the general patterns of nest success related to microhabitat as presented here, and lumping of years allowed examination of microhabitat choices and their fitness consequences over the long term.

Microhabitat was measured generally following the Breeding Biology Research and Monitoring Database (BBIRD) sampling protocol. ${ }^{1}$ Briefly, vegetation was measured on three sampling arrays: (1) nest sites, (2) non-use sites, and (3) stratified random sites. Nest sites: Vegetation features at nest sites were measured in a sampling plot centered on the nest (see next paragraph for details). Non-use sites: Non-use sites were located $35 \mathrm{~m}$ from the nest site in a direction parallel to the drainage to maintain the vertical position on the side slope. The nearest plant to the $35-\mathrm{m}$ point that was of the same species used for the nest (i.e., nest placed under or in that plant) formed the center of the nonuse sampling site. Stratified random sites: Vegetation showed a clear gradient from top to bottom of the sides of drainages and so each drainage was sampled in three strata (lower, middle, and upper one-third of the sides of the drainage). Each drainage had stations marked at 25-m intervals down the center of the drainage to aid nest location and other activities. Stations were picked that divided the drainage evenly into five locations and sampling sites were established in a direction perpendicular to the drainage to move up the side of the drainage valley. Sampling sites were randomly located along this perpendicular gradient in each of the strata.

Habitat was measured in a circle of 5-m radius, nested in a circle of $11-\mathrm{m}$ radius, at each of the three sampling-point types (nest, non-use, random). The $5 \mathrm{~m}$ radius circle was used to count understory plants and the $11 \mathrm{~m}$ radius circle was used for canopy trees. Numbers of stems of all understory woody plant species were counted separately by species and by size classes: $\mathrm{dbh}<2.5 \mathrm{~cm}, 2.5-8 \mathrm{~cm}, 8-23 \mathrm{~cm}$. Small conifers

${ }^{1} \mathrm{URL}=\langle$ http://pica.wru.umt.edu/bbird $\rangle$ 
(Douglas-firs, white firs, ponderosa pines, white pines) in the understory were counted by height classes: $<1$ $\mathrm{m}, 1-3 \mathrm{~m}, 3-5 \mathrm{~m}$ tall. Canopy trees were counted in the $11 \mathrm{~m}$ radius circle at the following sizes: dbh 8 $23 \mathrm{~cm}, 23-38 \mathrm{~cm}$, and $>38 \mathrm{~cm}$. The $5 \mathrm{~m}$ radius circle was divided into four sections using string and stakes to increase accuracy of counts and to eliminate duplicate counts of shrub stems. In addition, percentage ground cover comprised of green vegetation was measured in each quadrant by ocular estimation and averaged over all four quadrants.

\section{Data analyses}

Discriminant function and correlation analyses of the random samples among strata (lower, middle, and upper one-third) were used to reduce the number of variables based on multicollinearity of variables. Densities of different size classes of the same plant species showed strong positive correlations and demonstrated the same patterns along the gradient sampled by the random samples. Hence, size classes of plant species were lumped. Also, Douglas-fir vs. white fir and white pine vs. ponderosa pine each showed positive correlations and were lumped as firs [even though Pseudotsuga menziesii is not a true fir] and pines, respectively. I ended up with seven main variables that were used to examine vegetation patterns and these included all the main life forms of vegetation that nests were placed directly under or in: numbers of stems of maple, locust, oak, small firs $(<3 \mathrm{~m}$ tall $)$, small pines $(<3 \mathrm{~m}$ tall), total stems of all woody plants, and percentage ground cover. These seven variables were used in analyses of the vegetation gradient and for comparing random, non-use, and nest sites. Discriminant function analyses of differences among bird species included dummy variables for the plant species that the nest was placed in or under.

Multivariate analysis of variance was used initially to test for differences in the habitat variables among the three sampling sites (random, non-use, nest) for each bird species. For all species, the multivariate analysis of variance was significant and univariate analysis of variance was used to examine variation in habitat among the three sampling sites (only these univariate analyses are reported in Results because all multivariate analyses were highly significant). These univariate analyses were followed with a least significant difference test to examine differences in nest vs. random and nest vs. non-use sites.

I tested for habitat differences among bird species within ground- and shrub-nesting guilds. The same approach described above was used, where multivariate analysis of variance was first conducted and followed by univariate analysis of variance. Habitat variables were used to discriminate among species within each of the two nesting guilds using stepwise discriminant function analysis. Covariance matrices were tested for homogeneity using Box's $M$ criterion. The matrices showed significant heteroscedasticity $(P<0.05)$. Thus, separate group covariance matrices were used (Hand 1981, Williams 1983). Mahalonobis distance (minimum $D^{2}$ ) between group centroids was used for maximizing separation of groups. Finally, structure coefficients were obtained from discriminant analysis to determine correlations of variables with the discriminant functions.

Daily survival rates were calculated for preferred vs. other nest sites. Differences in daily mortality rates between preferred vs. other nest sites were tested using program CONTRAST (Hines and Sauer 1989). To estimate the form of natural selection, fitness surfaces for nest survival relative to habitat features that proved to be important to nest site preferences were estimated using cubic spline regression (Schluter 1988), a nonparametric technique. Cubic spline regression was applied to binomial (failed vs. survived) data and also to the minimum number of days that the nest was known to have survived from laying of the first egg. Results were essentially the same, so only the results for the binomial analyses are presented. Confidence limits for splines were estimated by bootstrapping, in which the original data were resampled 200 times (Schluter 1988). Relative selection intensity was estimated as the coefficient of variation in relative fitness, measured as predicted fitness (Schluter 1988). Analyses were completed using software provided by D. Schluter. Selection differentials and selection gradients were estimated following methods described in Lande and Arnold (1983), Schluter and Smith (1986), Schluter (1988), and Smith (1990). In general, I estimated the selection differential, $s$, as the slope of the univariate regression of relative fitness on standardized characters. The selection differential measures phenotypic responses to selection on correlated traits. In the case of this study, I used direct measures of habitat features as the phenotypic character of interest. Natural selection is acting on behavior (choice) of organisms, and I assume that the vegetation measurements reflect phenotypic variation in behavioral choices on which selection acts (see Jaenike and Holt 1991). I estimated the standardized directional selection gradient, $B$, as the partial regression coefficients of relative fitness vs. all critical habitat variables. This approach included an assumption that selection was not acting on other unmeasured traits that are correlated with the traits being measured (Schluter and Smith 1986, Price and Boag 1987). As I show in this article, the habitat variables that I used in these analyses were identified based on extensive and careful study of species preferences and were directly related to specific vegetation where nests were placed. Thus, habitat features used in these analyses seemed to be directly chosen by birds.

\section{RESULTS}

\section{Vegetation gradient}

Vegetation varied up the sides of drainages. New Mexican locust is shade-intolerant and xeric-tolerant 


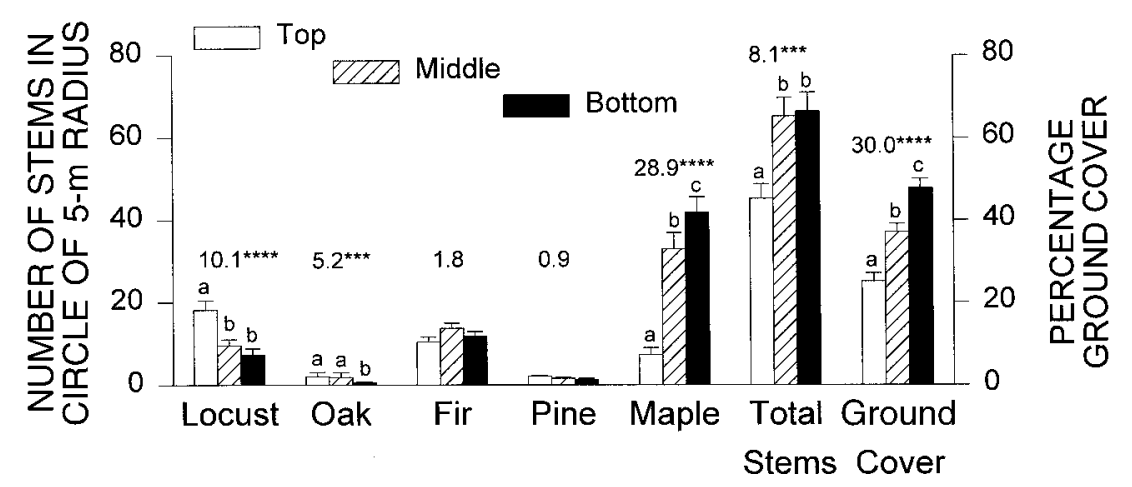

FIG. 2. Abundances of plant species in the lower, middle, and upper one-third of the sides of drainages. Twenty drainages were studied, and stem densities of woody plants (mean and $1 \mathrm{SE}$ ) were measured in circular plots of 5-m radius in the lower, middle, and upper one-third of the sides of the drainages $(n=101$ plots per stratum $=303$ plots total $)$. Differences among strata for each plant type were tested with ANOVA; numbers above each group of bars are $F$ values, and different lowercase letters above individual bars indicate differences $(P<0.05)$ between strata based on least significant difference test. Significance of $F$ values is: $* P<0.05$, $* * P<0.01$, $* * * P<0.001$, $* * * * P<0.0001$, with $\mathrm{df}=2,301$ in all cases. Vegetation for which stem densities were determined (left-hand vertical axis) included New Mexican locust (Robinia neomexicana), Gambel's oak (Quercus gambelii), canyon maple (Acer grandidentatum), small ( $<3 \mathrm{~m}$ tall) firs (Abies concolor, Pseudotsuga menziesii), small ( $<3 \mathrm{~m}$ tall) pines (Pinus ponderosa, Pinus strobiformes), and total woody stems of all plant species; percentage ground cover comprising green vegetation is also shown (right-hand vertical axis).

(Peattie 1953, Isely and Peabody 1984) and Gambel's Oak also is xeric-tolerant and both were more abundant in the upper than in the middle or lower strata of the sides of the drainage (Fig. 2). Canyon maple is associated with mesic conditions (Peattie 1953, Barker 1977, Barker et al. 1982) and maple, total stems, and ground cover were greater in the lower than in the middle and upper strata (Fig. 2). Maple made up most $(63 \%)$ of the total stems, so variation in total stems was largely driven by maple $(r=0.81, P<0.0001)$. Small $(<3 \mathrm{~m}$ tall $)$ firs were abundant while pines were not, but neither conifer type varied among strata. Thus, vegetation defined a moisture gradient with mesicadapted plants (maple, total woody stems, green ground cover) being greater in the lower reaches of the drainage, xeric-adapted plants (locust, oak) being more abundant at higher reaches and conifers (firs and pines) showing no clear pattern.

Discriminant function analysis yielded a single highly significant axis $\left(\chi^{2}=169.0, P<0.0001\right)$ that strongly discriminated strata from each other (Mahalanobis distances $-P<0.0001$ for all pairwise comparisons of strata). A stepwise procedure included all variables except total stems and pine. Total stems was excluded because of its collinearity with maple stems. Pine simply did not show any tendencies to discriminate among strata and it was never used for nesting by any of the species studied here. The structure coefficients (SC) showed high positive relationships for maple stems (SC $=0.51)$ and green ground cover $(\mathrm{SC}=0.52)$, negative relationships for stems of locust $(\mathrm{SC}=-0.31)$ and oak $(\mathrm{SC}=-0.18)$, and low loading for small firs $(\mathrm{SC}=$ 0.07). This canonical axis classified $61.4 \%$ of the sites in their correct strata. Lower and upper strata showed the greatest classification accuracy with $68.3 \%$ and
$76.2 \%$ correct classifications, respectively. In each of these two cases, the strata were most often incorrectly classified as the middle stratum $(22.8 \%$ and $16.8 \%$, respectively). The middle stratum showed the weakest discrimination with only $39.6 \%$ of the sites being correctly classified. In short, the middle of the gradient overlapped the two ends of the gradient, while the two ends were highly differentiated from each other. Moreover, this differentiation was obtained with a relatively small set of five variables (numbers of stems of maple, locust, small firs, oak, and green ground cover).

\section{Vegetation differences among random, non-use, and nest sites within species}

Ground-nesting species.-Nest sites differed from random sites for most of the habitat variables for all ground-nesting species (Fig. 3), showing that nest site selection is decidedly nonrandom. Nest sites generally differed from non-use sites in only one or two variables and these were the same variables that showed the greatest difference between nest and random sites (Fig. 3 ). The habitat differences reflected relative positions on slopes. Orange-crowned Warblers commonly nested in the bottom of drainages or low on the slope and nest sites had more maple than random and non-use sites (Fig. 3). Red-faced Warblers also nested relatively low on slopes and chose nest sites that had more small firs than non-use or random sites. Dark-eyed Juncos were the most catholic in their nest position on the slope and nested in the open rather than under woody vegetation. As a result, nest sites of Dark-eyed Juncos had high ground cover, but also more locust, reflecting a tendency to nest somewhat high on the slope and in relatively xeric conditions. Finally, Virginia's Warblers 


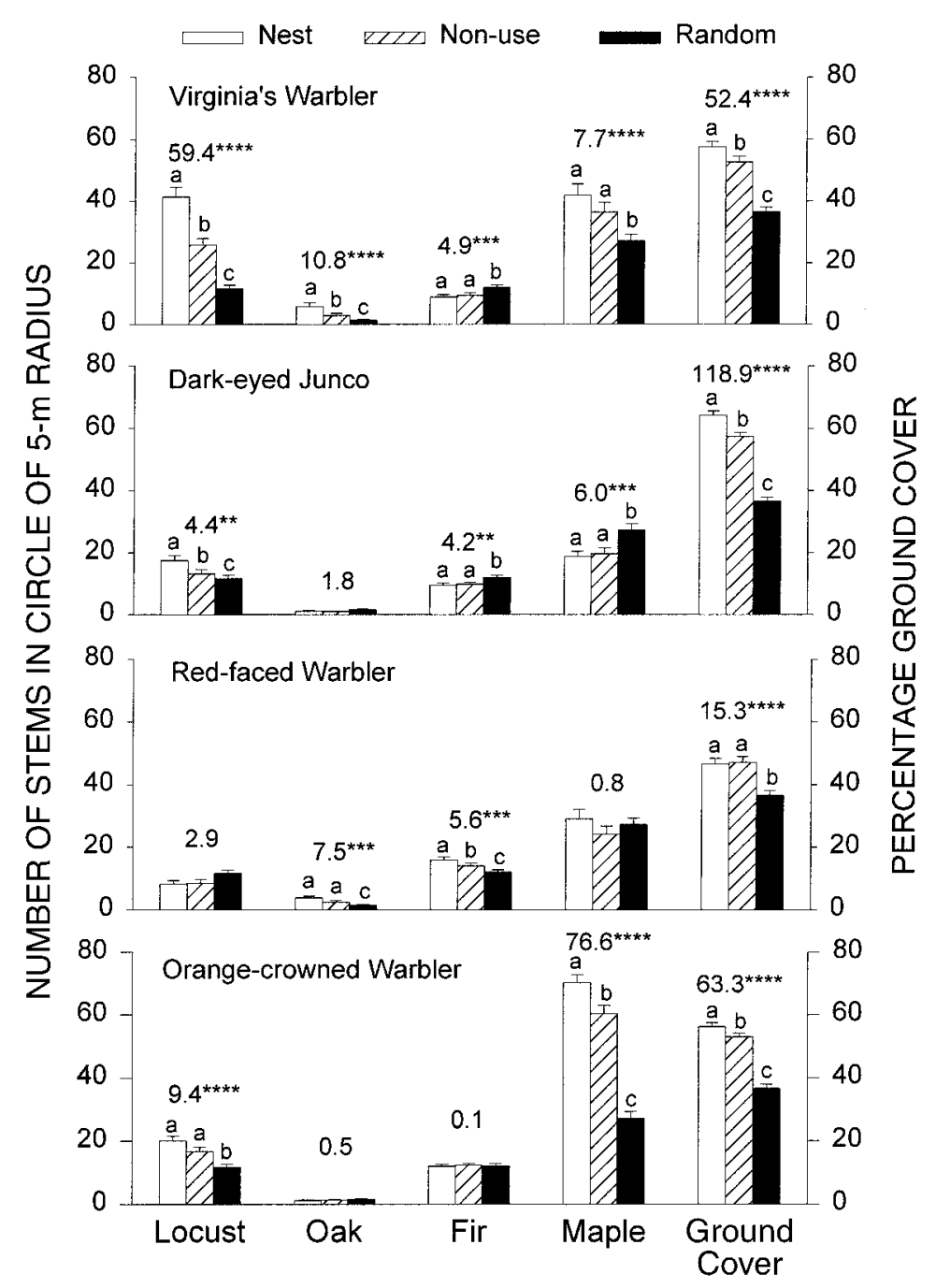

FIG. 3. Abundance of plant species in circular plots of 5-m radius at the nest sites of ground-nesting bird species, paired non-use sites (centered on a woody stem nearest to a point that was $35 \mathrm{~m}$ from the nest in a direction parallel to the contour of the drainage and that was of the same plant species that the nest was located under), and random sites. Data are means and 1 SE. Numbers above each group of bars are $F$ values from ANOVA; different lowercase letters above individual bars indicate differences $(P<0.05)$ between nest sites vs. non-use and random sites based on least significant difference tests. Significance of $F$ values is: $* P<0.05$, $* * P<0.01$, *** $P<0.001$, ****P<0.0001. Degrees of freedom are as follows: Orange-crowned Warbler $=2,1026$; Red-faced Warbler $=2,729$; Dark-eyed Junco $=2,919$; Virginia's Warbler $=2,631$.

nested highest on the slope and nest sites had more locust and oak (Fig. 3).

Shrub-nesting species.-As with ground-nesters, nest sites of shrub-nesting species differed from random sites in many of the habitat variables, but only for one or two of the variables when compared with nonuse sites (Fig. 4). MacGillivray's Warblers mostly nested in or near the bottom of drainages and chose nest sites with an abundance of maple. Hermit Thrush usually nested low on the slope and chose nest sites that had an abundance of small firs (Fig. 4). Green-tailed Towhees nested high on slopes and chose nest sites with an abundance of locust and greater ground cover (Fig. 4).

\section{Nest patch differences among species}

Ground-nesting species.-The foregoing analyses showed that each species exhibited nonrandom nest site selection. Discriminant function analysis was used to examine whether these nonrandom choices differed among species. Habitat variables (ground cover, maple, locust, small firs, and oak) were included in the analysis along with four dummy variables representing the plant species or site under which nests were placed (maple, locust, fir, or open). Three highly significant $\left(\chi^{2}>130\right.$, $P<0.0001$ in all cases) discriminant function axes strongly differentiated nest sites of all species from each other $(F>19.0, P<0.0001$, df $=8,1036$ for all pairwise comparisons). Nest sites of each species 


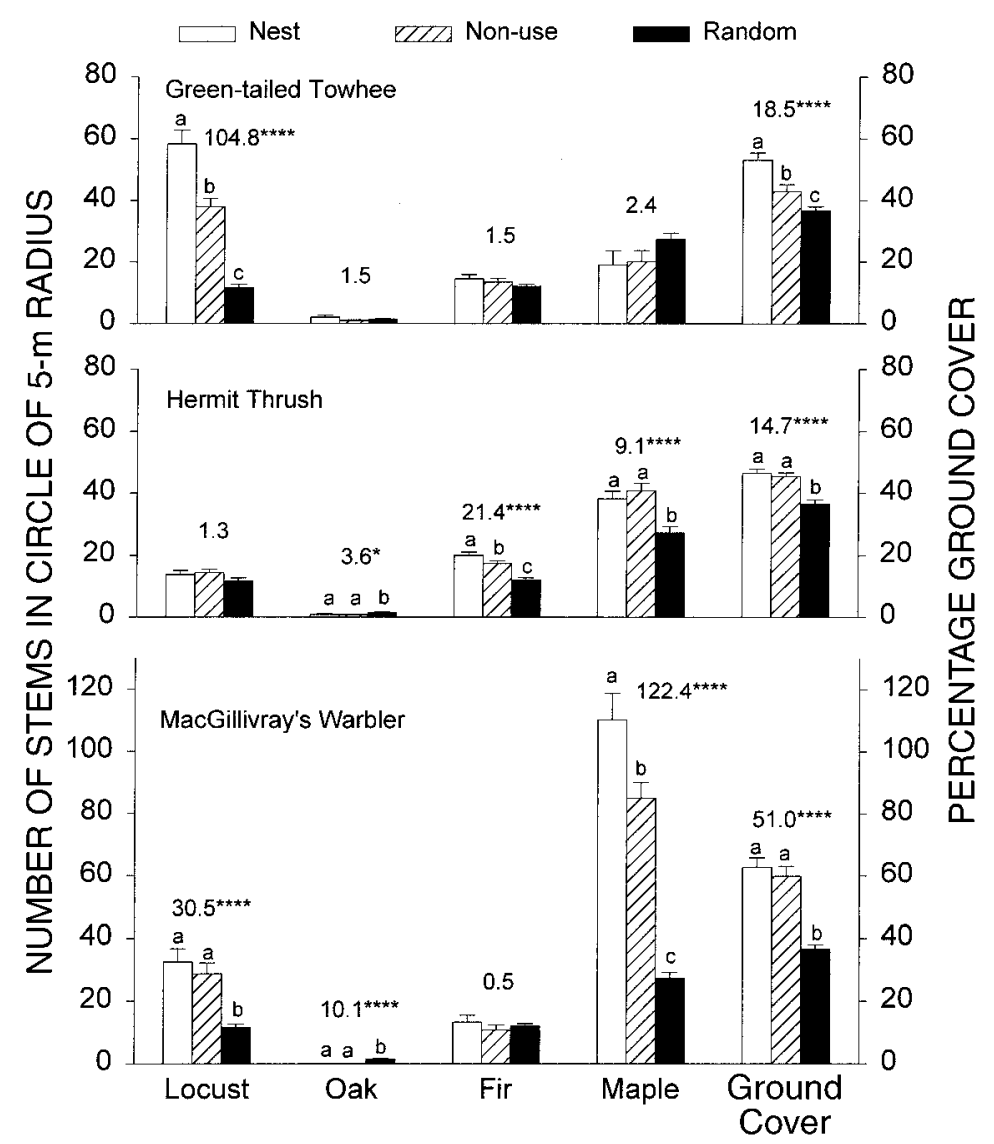

FIG. 4. Abundance of plant species in circular plots of 5-m radius at the nest sites of shrub-nesting bird species, at paired non-use sites (centered on a woody stem nearest to a point that was $35 \mathrm{~m}$ from the nest in a direction parallel to the contour of the drainage and that was of the same plant species that the nest was located under), and at random sites. Data are means and 1 SE. Numbers above each group of bars are $F$ values from ANOVA; $F$-value testing and display of results are as in Fig. 3. Degrees of freedom are as follows: MacGillivray's Warbler $=2,449$; Hermit Thrush $=2$, 982; Green-tailed Towhee $=2,573$.

were correctly classified more often than not (Table 1). Nest sites of Orange-crowned and Virginia's Warblers were most often misclassified as nest sites of each other, while nest sites of Red-faced Warblers and Dark-eyed Juncos were most frequently misclassified as belonging to each other, with nest sites of Red-faced Warblers also being misclassified as those of Orange-crowned Warblers often (Table 1).

The correct and incorrect classifications reflected general differences and similarities in nest sites of the four ground-nesting bird species (Fig. 5). In particular, Virginia's Warblers chose nest sites with more locust and oak than the other species (Fig. 5), but they also chose sites with an abundance of maple causing their misclassifications as Orange-crowned Warblers (see Fig. 5 vs. Table 1). Dark-eyed Juncos chose nest sites with more ground cover and fewer maple stems (indicating choice of open areas with less woody vege-

TABLE 1. Classification of nest sites (percentage of cases classified as nests of each species) from discriminant function analysis of nest sites of the four ground-nesting bird species based on separate covariance matrices.

\begin{tabular}{lcccc}
\hline \hline & \multicolumn{3}{c}{ Predicted group membership } \\
\cline { 2 - 5 } \multicolumn{1}{c}{$\begin{array}{c}\text { Ground-nesting } \\
\text { species }\end{array}$} & $\begin{array}{c}\text { Orange- } \\
\text { crowned } \\
\text { Warbler }\end{array}$ & $\begin{array}{c}\text { Red-faced } \\
\text { Warbler }\end{array}$ & $\begin{array}{c}\text { Dark-eyed } \\
\text { Junco }\end{array}$ & $\begin{array}{c}\text { Virginia's } \\
\text { Warbler }\end{array}$ \\
\hline Orange-crowned Warbler & 60.7 & 7.4 & 12.1 & 19.8 \\
Red-faced Warbler & 23.6 & 36.6 & 26.9 & 13.0 \\
Dark-eyed Junco & 13.2 & 13.2 & 60.6 & 12.9 \\
Virginia's Warbler & 25.3 & 9.0 & 16.9 & 48.8 \\
\hline
\end{tabular}




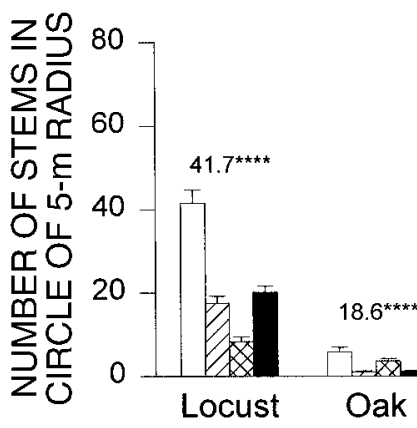

Orange-crowned Warbler, $n=358$

FIG. 5. Abundance of plants (numbers of woody stems in a circle of 5-m radius) at nest patches of ground-nesting birds
(mean and $1 \mathrm{SE}$ ). Differences among bird species for each plant type were tested with ANOVA, and the number above each group of bars is the $F$ value, where significance is: $* P<0.05, * * P<0.01, * * * P<0.001, * * * * P<0.0001$, with $\mathrm{df}=3$, 1048 in all cases.

tation). Red-faced Warblers chose nest sites with more small firs and fewer locust stems (Fig. 5). Finally, Orange-crowned Warblers chose nest sites with more maple than the other species (Fig. 5). These vegetation features that differentiated each species from other species were the same ones that differentiated nest sites from non-use sites within each species (see Results: Vegetation differences among random, non-use, and nest sites within species).

Non-use sites were located within the same strata as the nest and centered on the same plant species as used for the nest, but nest sites differed from non-use sites (see Fig. 3). Nonetheless, discriminant function analysis of non-use sites produced three highly significant $\left(\chi^{2}>61, P<0.0001\right.$ in all cases) axes that differentiated species from each other $(F>11.6, P<0.0001$, $\mathrm{df}=6,1037$ for all pairwise comparisons), although not quite as clearly as did nest sites. These differences in non-use sites among species indicated that species were nonrandomly choosing differing microhabitat types, and the differences between nest sites and nonuse sites (Fig. 3) indicated that species were nonrandomly choosing nest sites within microhabitat types.

Vegetation in the nest patch also differed among nests placed under different plant species (Fig. 6). For example, nests placed under locust had more locust in the nest patch than did nests placed under other vegetation types, for each bird species. Nests placed under small firs had more small firs in the patch than nests placed under other vegetation types (Fig. 6). Yet, patch characteristics also differed among bird species when they chose the same nesting substrate (Fig. 6). Moreover, nest patches included elements of vegetation preferences of each bird species even when they chose the same nest substrate type; absolute abundance of stems changed among the four nest types, but relative ranking of stem abundance for a stem type remained relatively similar among bird species regardless of nest site (Fig.
6). In general, Orange-crowned Warblers had more maple stems, Red-faced Warblers had more fir stems, Dark-eyed Juncos had more ground cover, and Virginia's Warblers had more locust stems in their nest patches compared to the other bird species regardless of the plant type that nests were placed under (Fig. 6).

Shrub-nesting species.-Discriminant function analysis yielded two $\left(\chi^{2}>106, P<0.0001\right.$ in both cases) canonical axes that strongly differentiated nest sites of shrub-nesting species $(F>64.0, P<0.0001$, df $=2$, 497 for all pairwise comparisons). Nest sites of all three shrub-nesters were correctly classified most of the time (Table 2), reflecting strong differences among species (Fig. 7). MacGillivray's Warblers chose nest sites with more maple than the other species (Fig. 7). Green-tailed Towhees chose nest sites with more locust and oak and Hermit Thrushes chose nest sites with more small firs than other species (Fig. 7). Both Green-tailed Towhees and MacGillivray's Warblers were most often misclassified as Hermit Thrushes, because they both used firs for nest sites and chose patches dominated by fir, similar to the choices of Hermit Thrush.

All three shrub-nesters mostly frequently placed their nests in small firs. If analyses were restricted to nests placed in small firs, the same results were found: Discriminant function analysis of nest patches for nests placed in small firs yielded two $\left(\chi^{2}>39, P<0.0001\right.$ in both cases) discriminant function axes that strongly differentiated species from each other $(F>21.0, P<$ 0.0001 , df $=2,411$ for all pairwise comparisons). Thus, species chose differing nest microhabitats even when they chose the same nest substrate. In fact, discriminant function analysis of non-use sites produced two highly significant $\left(\chi^{2}>73, P<0.0001\right.$ in all cases $)$ canonical axes that also differentiated species from each other $(F>22, P<0.0001$, df $=4,599$ for all pairwise comparisons), again indicating that species were choosing nests in different microhabitats. 


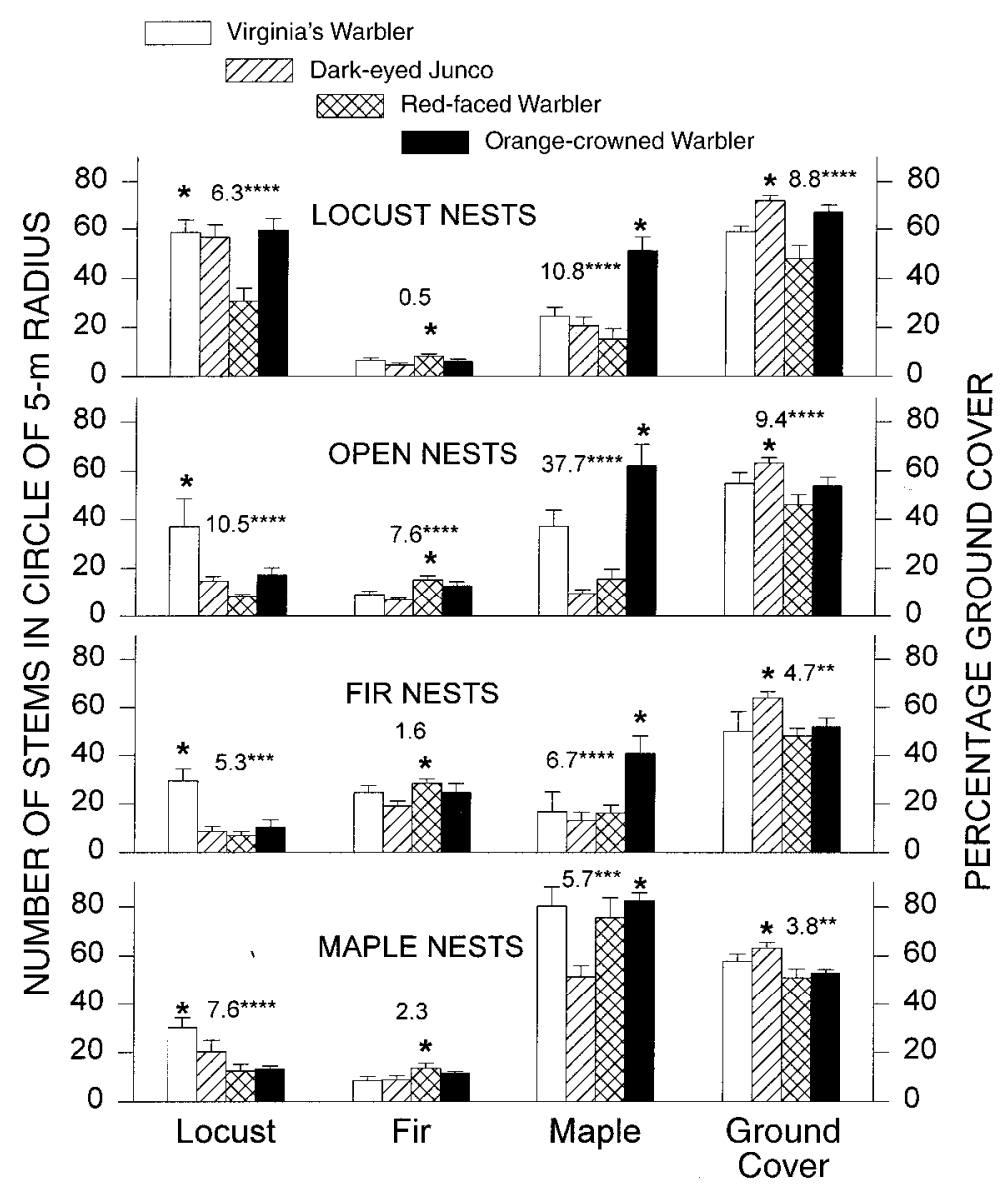

FIG. 6. Abundance of plants in circular patches of 5-m radius for nests placed under locust, fir, or maple stems, or placed in the open (not under a woody stem). Data are means and 1 SE. Differences among bird species for each plant type were tested with ANOVA, and the number above each group of bars is the $F$ value, where significance is: $* P<0.05$, $* * P<$ $0.01, * * * P<0.001, * * * * P<0.0001$. Degrees of freedom are as follows: locust nests $=3,198$; open nests $=3,262 ;$ fir nests $=3,202$; maple nests $=3,377$. Absolute abundance of stems changed among the four nest types, but relative ranking of stem abundance for a stem type remained generally similar among bird species regardless of nest site. Orange-crowned Warblers chose nest patches with more maples than other bird species even when nesting under locust, fir, or in the open. Red-faced Warblers chose nest patches that contained more small firs than other bird species. Dark-eyed Juncos chose nest patches with more ground cover. Virginia's Warblers chose nest patches that contained more locusts than other bird species. Single large asterisks are shown above the stem type that characterized each bird species.

\section{Nest patch preferences}

The habitat feature that differentiated nest sites from non-use sites within species (Figs. 3, 4) also differentiated nest sites of bird species from each other (Figs.

TABLE 2. Classification of nest sites (percentage of cases classified as nests of each species) from discriminant function analysis of nest sites of the three shrub-nesting bird species based on separate covariance matrices.

\begin{tabular}{lccc}
\hline \hline & \multicolumn{3}{c}{ Predicted group membership } \\
\cline { 2 - 4 } & $\begin{array}{c}\text { MacGillivray's } \\
\text { Warbler }\end{array}$ & $\begin{array}{c}\text { Hermit } \\
\text { Thrush }\end{array}$ & $\begin{array}{c}\text { Green- } \\
\text { tailed } \\
\text { Towhee }\end{array}$ \\
\hline MacGillivray's Warbler & 67.9 & 24.7 & 7.4 \\
Hermit Thrush & 11.8 & 79.4 & 8.8 \\
Green-tailed Towhee & 9.4 & 36.2 & 54.3 \\
\hline
\end{tabular}

5-7) and typified the dominant vegetation type that was used most frequently by each bird species (Fig. 8). For example, Virginia's Warblers chose nest sites with more locust than at random and non-use sites (Fig. 3) and compared to nests of other ground-nesting bird species ( Figs. 5, 6) and Virginia's Warblers chose microhabitats dominated by locust more frequently than any other dominant vegetation type (Fig. 8). The same consistent relationships existed for all the other groundand shrub-nesting species (Fig. 8). Given that all microhabitats were available to all individuals of all species (see Fig. 1) and that nest sites were chosen nonrandomly in microhabitats that differed among species (Figs. 3-7), then I took frequency of use of vegetation types (Fig. 8) as indicative of preference in this study system (preferences could differ elsewhere [Thompson 1993]). Thus, the vegetation type that was used most 


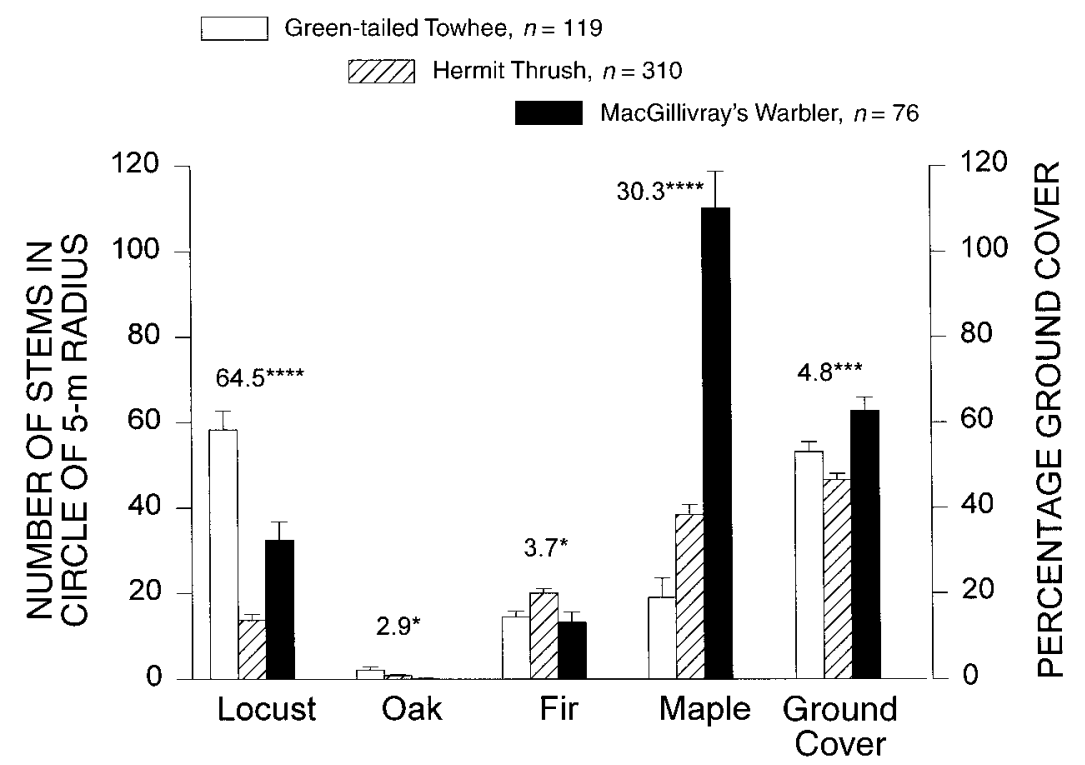

FIG. 7. Density of woody plants at nest patches (mean and 1 SE numbers of stems in a circle of 5-m radius) of shrubnesting birds. Differences among bird species for each plant type were tested with ANOVA, and the number above each group of bars is the $F$ value, where significance is: $* P<0.05$, $* * P<0.01$, *** $P<0.001$, and $* * * * P<0.0001$, with df $=2,503$ in all cases.

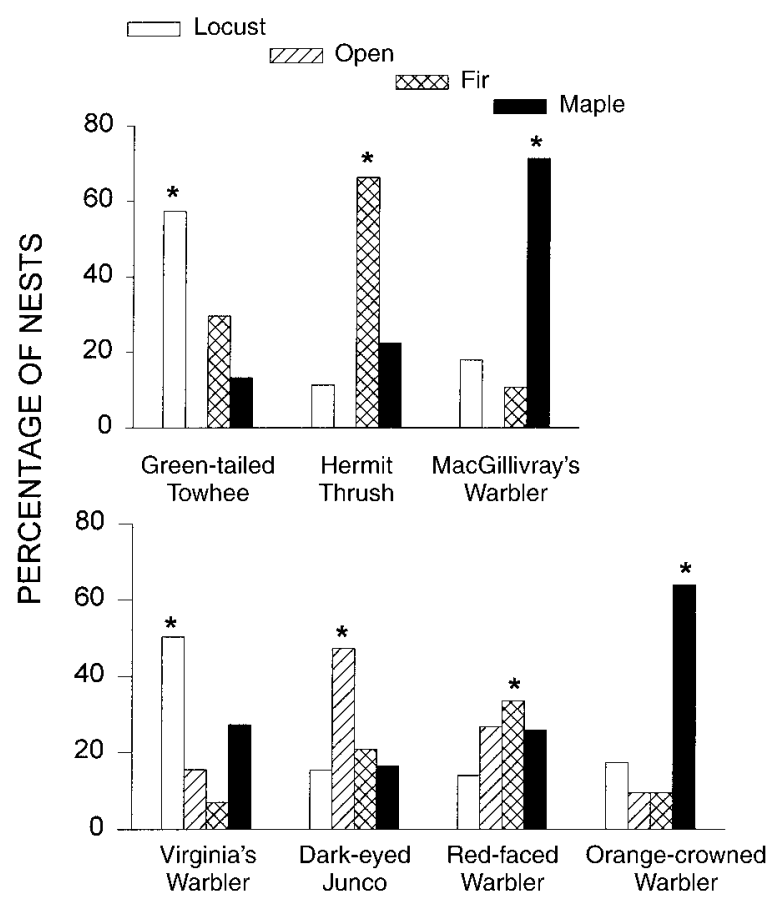

FIG. 8. Frequency (percentage of cases) that nests were placed in each microhabitat for the shrub- and ground-nesting bird species. Microhabitat types are defined by the dominant vegetation type in the nest patch (a circle of 5-m radius). "Open" nests represent nests placed in the open or under grass rather than under a woody vegetation stem. Asterisks highlight the preferred (most frequently used) microhabitat type for each bird species. frequently was considered the preferred microhabitat and is illustrated in Fig. 8.

\section{Natural selection on microhabitat choices}

Nesting success, as measured by daily survival rate (probability of surviving per day), was greater at preferred than nonpreferred nest sites for all bird species (Fig. 9). Note also that daily survival rates at nonpreferred nest sites showed a consistent decline from species that nested high on the slope (i.e., Virginia's Warbler among ground-nesters, Green-tailed Towhees among shrub-nesters) to species that nested low on the slope (e.g., Orange-crowned Warblers among groundnesters, Hermit Thrushes among shrub-nesters) $\left(\chi^{2}=\right.$ 68.7, $P<0.0001$ for ground-nesters, $\chi^{2}=10.7, P=$ 0.0048 for shrub-nesters).

Three of the four ground-nesting species showed positive selection differentials and gradient coefficients (Table 3) for the vegetation type that typified its preferred vegetation type as illustrated in Fig. 8. The one exception was Dark-eyed Juncos, which did not show directional selection for any of the four main habitat variables (Table 3). Virginia's Warblers showed positive directional selection for numbers of locust stems in the nest patch (Fig. 10, Table 3), which typified preferred sites of Virginia's Warblers (Fig. 8). Virginia's Warblers also showed positive, but nonlinear directional selection for maple (Fig. 10, Table 3), which was the second most frequently used vegetation type (Fig. 8). In contrast, Orange-crowned Warblers showed strong positive directional selection for maple, their preferred nest site, and mild negative directional selection for locust (Fig. 11, Table 3). Red-faced Warblers 

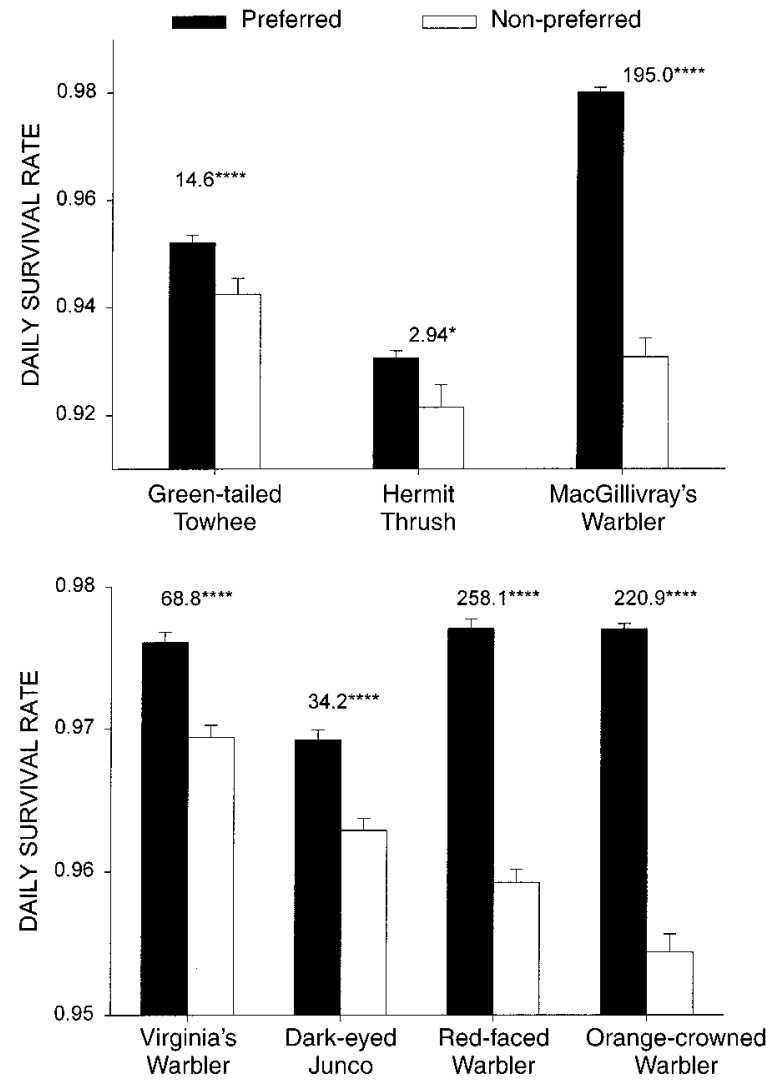

FIG. 9. Daily survival rates (probability of survival per day, mean and $1 \mathrm{SE}$ ) for nests placed in preferred and nonpreferred microhabitats. Preferred microhabitats are defined as the vegetation type that was used most frequently, and nonpreferred microhabitats are all other vegetation types (Fig. 8 ). The number above each pair of bars is the $\chi^{2}$ statistic from the test of differences in daily survival rate for preferred vs. nonpreferred sites based on Program Contrast (Hines and Sauer 1989): $* P<0.05, * * P<0.01$, $* * * P<0.001$, **** $P$ $<0.0001$

showed positive directional selection for numbers of small firs, their preferred nest site, but showed negative directional selection for maple (Table 3).

Green-tailed Towhees showed positive directional selection for numbers of locust stems (Table 4), its preferred nesting microhabitat (Fig. 8). MacGillivray's Warblers showed strong positive directional selection for maple (Table 4), weak positive selection for num- bers of small firs, and weak negative selection for percentage ground cover. Hermit Thrushes showed positive directional selection for numbers of small firs and negative directional selection for percentage ground cover (Table 4).

\section{DISCUSSION}

\section{Identification of habitat preferences}

Studies of habitat preferences in birds are often based on correlations between density and habitat measurements, which is a highly indirect approach. Such approaches may identify habitat features that have no direct bearing on choices and no influence on fitness components (Martin 1992). Measurement of habitat features that are directly chosen for activities that affect fitness, such as choice of plants specifically used for placing nests in or under, should more directly reflect features that are being chosen, at least at the microhabitat scale. However, even at such scales, tests need to be interpreted cautiously. Nest sites differed from random sites in many of the habitat features measured in this study (see Figs. 3, 4), but such comparisons do not necessarily identify habitat features that are critical to choices. Indeed, many habitat features that differed between nest sites and random sites showed no relationship to nest site preferences nor did they exhibit significant directional selection coefficients. As one example, comparisons of nest sites of Orange-crowned Warblers to random sites showed that nest sites had more maple and more locust (Fig. 2). This comparison could suggest that Orange-crowned Warblers chose sites with more locust. Yet, selection potentially acted against choice of locust (see Fig. 11, Table 3), although locust may simply have been unimportant to habitat choice or to natural selection on habitat choice (see Discussion: Adaptiveness and selection on preferences). In short, differences between nest sites and random sites could identify important habitat features (i.e., maple), but could also produce significant differences in habitat features that were unimportant to choices (i.e., locust). The same patterns are true for all species.

In this study, habitat features that showed the greatest difference between nest and random sites were the same features that differed between nest and non-use sites (Figs. 3, 4) and that differentiated nest site choices of species from each other (Figs. 5, 7). These same veg-

TABLE 3. Standardized directional selection differentials $(s)$ and selection gradients $(\beta)$ for nest survival related to critical vegetation features for ground-nesting bird species. Data are means \pm 1 SE.

\begin{tabular}{|c|c|c|c|c|}
\hline \multirow[b]{2}{*}{ Vegetation } & \multicolumn{2}{|c|}{ Virginia's Warbler } & \multicolumn{2}{|c|}{ Dark-eyed Junco } \\
\hline & $s$ & $\beta$ & $s$ & $\beta$ \\
\hline Locust & $0.112 \pm 0.047 * *$ & $0.119 \pm 0.048 * *$ & $0.055 \pm 0.056$ & $0.071 \pm 0.057$ \\
\hline Small fir & $-0.065 \pm 0.079$ & $-0.018 \pm 0.081$ & $0.065 \pm 0.062$ & $0.078 \pm 0.064$ \\
\hline Maple & $0.123 \pm 0.063 * *$ & $0.137 \pm 0.062 * *$ & $-0.021 \pm 0.087$ & $-0.031 \pm 0.088$ \\
\hline Ground cover & $0.066 \pm 0.069$ & $0.047 \pm 0.068$ & $-0.017 \pm 0.057$ & $-0.076 \pm 0.058$ \\
\hline
\end{tabular}

* $P<0.10$, ** $P<0.05, * * * P<0.001$. 

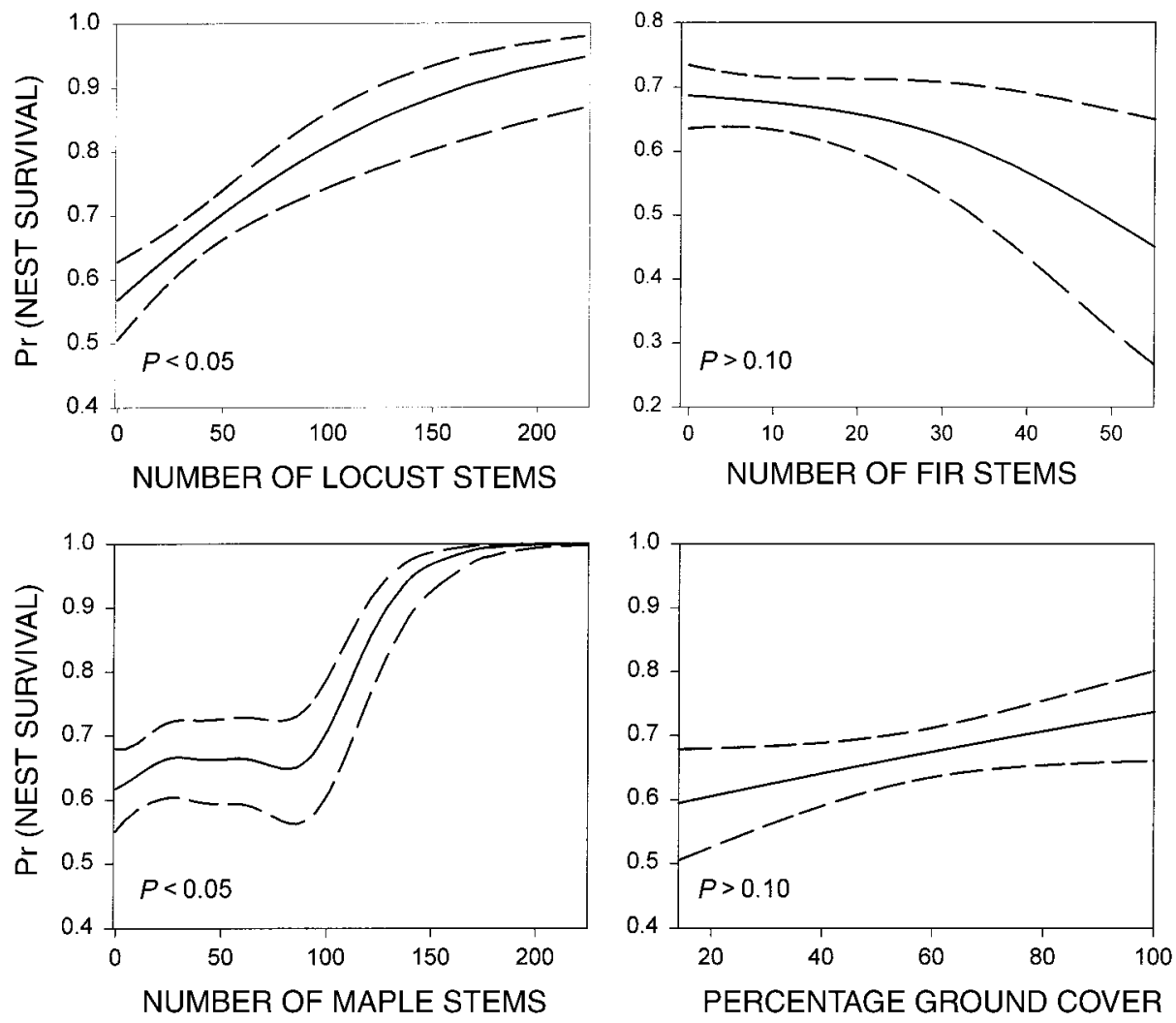

FIG. 10. Fitness surfaces (probability of nest survival) of Virginia's Warblers as a function of the four main vegetation features characterizing the habitat gradient and bird species' nesting preferences. Dashed curves show \pm 1 SE around the predicted probability of nest survival based on 200 bootstrap replicates of the fitness function. Significance levels are from Table 3.

etation features also reflected the dominant vegetation of nest sites that were used most frequently (i.e., preferred) by each species (Fig. 8). Frequency of use of dominant vegetation types provided an unambiguous indication of preferences here because the short nature of the gradient allowed all microhabitat types to be included in the territories and, hence, available to all individuals (see Fig. 1). In other situations, all microhabitats may not be available within each territory, and limited availability of particular microhabitats can yield restricted access to preferred microhabitats (see Dhondt et al. 1992, Petit and Petit 1996) such that use does not reflect preference if microhabitats are not equally available to all individuals. In short, determi- nations of habitat preferences need to be based on careful study and not simply on density or a comparison of used (e.g., nest) vs. random sites.

\section{Adaptiveness and selection on preferences}

Microhabitat preferences identified for each bird species studied here were clearly adaptive in that reproductive success was greater in preferred than nonpreferred microhabitats (Fig. 8). Moreover, positive directional selection coefficients for the habitat feature that typified preferred sites suggested that these preferences were under selection to be maintained (Tables 3, 4), with exception of Dark-eyed Juncos, which showed no significant selection for any of the measured

TABle 3. Extended.

\begin{tabular}{rrrrr}
\hline \hline \multicolumn{2}{c}{ Red-faced Warbler } & & \multicolumn{2}{c}{ Orange-crowned Warbler } \\
\cline { 1 - 2 }$s$ & $\beta$ & & $s$ & $\beta$ \\
\hline$-0.069 \pm 0.154$ & $-0.086 \pm 0.156$ & & $-0.097 \pm 0.053^{*}$ & $-0.065 \pm 0.056$ \\
$0.170 \pm 0.079^{* *}$ & $0.147 \pm 0.080^{*}$ & & $0.074 \pm 0.051$ & $0.076 \pm 0.051$ \\
$-0.179 \pm 0.087^{* *}$ & $-0.171 \pm 0.087^{* *}$ & & $0.194 \pm 0.046^{* * * *}$ & $0.208 \pm 0.047^{* * * *}$ \\
$-0.041 \pm 0.073$ & $-0.024 \pm 0.075$ & & $-0.041 \pm 0.049$ & $0.020 \pm 0.050$ \\
\hline
\end{tabular}


TABLE 4. Directional selection differentials $(s)$ and selection gradients $(\beta)$ for nest survival related to critical vegetation features for shrub-nesting bird species.

\begin{tabular}{|c|c|c|c|c|}
\hline \multirow[b]{2}{*}{ Vegetation } & \multicolumn{2}{|c|}{ Green-tailed Towhee } & \multicolumn{2}{|c|}{ MacGillivray's Warbler } \\
\hline & $s$ & $\beta$ & $s$ & $\beta$ \\
\hline Locust & $0.170 \pm 0.070 * *$ & $0.154 \pm 0.076^{* *}$ & $0.054 \pm 0.121$ & $0.074 \pm 0.115$ \\
\hline Small fir & $-0.133 \pm 0.097$ & $-0.061 \pm 0.110$ & $0.150 \pm 0.092$ & $0.152 \pm 0.089^{*}$ \\
\hline Maple & $0.041 \pm 0.104$ & $-0.043 \pm 0.106$ & $0.248 \pm 0.087 * * * *$ & $0.275 \pm 0.083 * * * *$ \\
\hline Ground cover & $0.083 \pm 0.103$ & $0.017 \pm 0.115$ & $-0.211 \pm 0.119 *$ & $-0.210 \pm 0.118^{*}$ \\
\hline
\end{tabular}

$* P<0.10, * * P<0.05, * * * * P<0.001$.

habitat features. This study system may be uncommon in the simplicity of the plant diversity that comprised and described the vegetation gradient and, hence, the habitat preferences of species. In many cases, only a single habitat feature (1) differentiated nest sites from non-use sites, (2) differentiated a species from other species, and (3) characterized preferred sites, and this feature was the only habitat feature showing significant directional selection. As a result, multivariate selection gradients $(\beta)$ generally did not differ from univariate directional selection differentials $(s)$ (see Tables 3,4$)$. However, some species had significant selection coefficients for an additional habitat feature. In most cases, this other significant selection coefficient was negative. These negative coefficients sometimes reflected a negative correlation between abundance of a
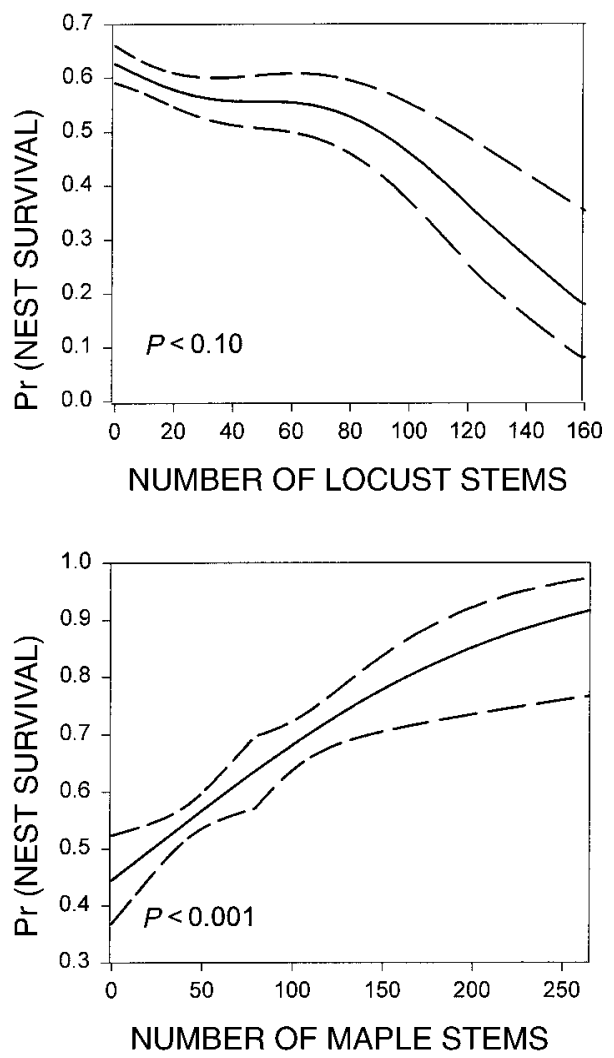

habitat feature and abundance of the habitat feature for which the stronger positive directional selection coefficient existed. For example, Orange-crowned Warblers had a positive directional selection coefficient for maple (Table 3, Fig. 11), which typified their preferred nest site (Figs. 3, 5, 8), and a negative directional selection coefficient for locust (Table 3, Fig. 11). Structure coefficients from discriminant function analysis of the vegetation gradient showed that maple loaded positively and locust loaded negatively (see Results: Vegetation gradient) illustrating that locust typified the opposite end of the vegetation gradient from maple (Figs. $1,2)$. Thus, negative selection on locust potentially reflected selection against nest site choices that were higher on the vegetation gradient and away from the preferred microhabitat of maple, rather than selection
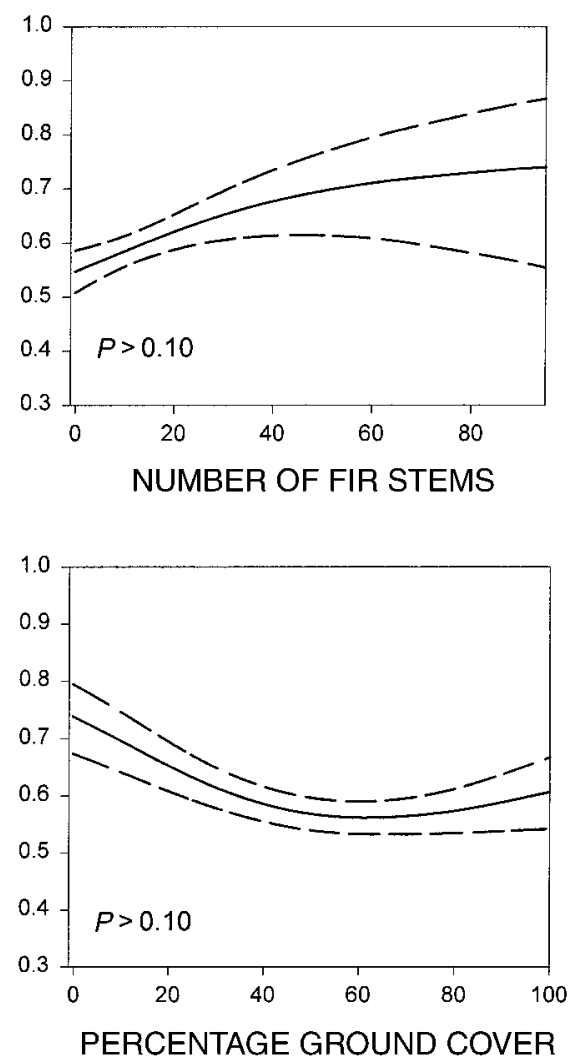

FIG. 11. Fitness surfaces (probability of nest survival) of Orange-crowned Warblers as a function of the four main vegetation features characterizing the habitat gradient and bird species' nesting preferences. Data are displayed as in Fig. 10. 
TABle 4. Extended.

\begin{tabular}{cc}
\hline \multicolumn{3}{c}{ Hermit Thrush } \\
\hline$s$ & $\beta$ \\
\hline$-0.234 \pm 0.141$ & $-0.190 \pm 0.145$ \\
$0.154 \pm 0.089 *$ & $0.134 \pm 0.088$ \\
$-0.176 \pm 0.119$ & $-0.130 \pm 0.120$ \\
$-0.234 \pm 0.098 * *$ & $-0.191 \pm 0.100^{*}$ \\
\hline
\end{tabular}

on choice of locust per se. In fact, the multivariate selection gradient $(\beta)$ indicated that locust was not under selection when selection on maple was considered (Table 3). Similarly, two shrub-nesting species, MacGillivray's Warblers and Hermit Thrushes, had negative selection coefficients for ground cover (Table 4). This relationship again probably reflected confounding among habitat variables given that the habitat feature (small firs), for which both species showed positive directional selection, was negatively correlated with ground cover. Moreover, nests were not placed in or near ground cover. Ultimately, habitat features that were directly chosen for placing nests in or under provided a clear biological basis for nest site choices, as reflected by the strong positive directional selection coefficients

The strong directional selection coefficients on habitat features typifying preferred sites brings up two related questions. First, given the fitness advantage of using preferred microhabitats, then why does variation in use of microhabitats exist? Second, why does the population not evolve to use the preferred conditions more frequently? The potential for evolution depends on selection differentials, but the strength of selection is also influenced by heritability of the trait (Endler 1986). I explicitly assumed here that quantitative measures of habitat features reflected choices and that habitat choice has a genetic basis and can evolve. Indeed, a variety of evidence suggests that habitat preferences have a genetic basis (see Thompson et al. 1990, Jaenike and Holt 1991). Yet, evidence also shows that birds can exhibit at least some behavioral plasticity in nest site choice as a function of previous success (reviewed in Martin 1992) and indicates that selection may be acting on a reaction norm of choices.

The variation in use of microhabitat types within each species (i.e., Fig. 8) may have arisen from four possible factors. First, variation in other environmental conditions, such as weather, may have caused variation in nest site choice along the microclimatic gradient (T. E. Martin, unpublished manuscript). Second, young birds may have used microhabitats other than the preferred one. Yet, age cannot fully explain the variation because some individuals have been banded and even returning individuals have been found to use microhabitats other than the preferred one (T. E. Martin, unpublished data). Third, birds commonly change nest site and microhabitat choices following early failure (reviewed in Martin 1992) so that some variation may reflect such responses. Finally, behavioral dominance among species (e.g., Morse 1974, 1976) may influence microhabitat choices in some cases. Virginia's Warblers showed positive directional selection for locust, their preferred nest sites, and also for maple (Fig. 10) their second preference (see Fig. 8). Orange-crowned Warblers used maple sites most frequently and are congeners with Virginia's Warbler. Orange-crowned Warblers are slightly larger and appeared behaviorally dominant in the field (T. E. Martin, personal observation), so use of maple by Virginia's Warblers may have been reduced by Orange-crowned Warblers. The decreased cost of using nonpreferred (e.g., lower-altitude) sites for species that mostly nest high on the slope (Fig. 9) suggested that use of lower sites may not be strongly selected against, but use of these lower sites may be restricted by behavioral interactions from species that are most common there. Existence of such interactions is speculative, however, and ultimately depend on experimental tests.

The bird species showed clear partitioning of microhabitat preferences along the gradient. Such partitioning of vegetation/microclimate gradients, often associated with elevational gradients, has been noted in other systems (e.g., Terborgh 1971, 1985, Smith 1977, Noon 1981, Karr and Freemark 1983, Remsen and Graves $1995 a, b)$. These microhabitat and elevational differences among species may reflect natural selection favoring habitat partitioning. Often, this selection is thought to be imposed by competition for food (e.g., Terborgh 1971, 1985, Noon 1981, Remsen and Graves $1995 a, b)$. Yet, overlap in nest microhabitat choices can produce fitness costs from predation that can favor partitioning (Martin 1988, 1993, 1996). On the other hand, choice of differing microhabitats that occur at different positions along microclimatic gradients could reflect choice of differing microclimatic conditions resulting from differing physiological tolerances (T. E. Martin, unpublished manuscript). Tests of such alternatives are needed because they explore the mechanistic basis of habitat preferences.

Use of nonpreferred nest sites clearly imposed a substantial fitness cost, which varied among species (Fig. 9). The vast majority (98\%) of nest mortality occurs from nest predation (Martin 1992; T. E. Martin, unpublished data), so use of nonpreferred nest sites imposes a cost from increased nest predation. This increase in nest predation could arise from several mechanistic alternatives: First, use of nonpreferred sites can increase overlap in nest site use among species, which can increase predation risk (Martin 1988, 1993, 1996). Second, species may be poorly adapted to alternative microhabitats because of characters set by their evolutionary history; background matching from plumage colors may be poor or behaviors near the nest may be more obvious in alternative microhabitats (Martin 1993, 1996). Alternatively, species may be more poorly adapted physiologically to nonpreferred sites, given 
that nonpreferred sites often reflect different positions on the microclimate gradient (T. E. Martin, unpublished manuscript). Variation in microclimate can influence incubation rhythms and activity at the nest, which may influence probability of attracting a predator (Weathers and Sullivan 1989). Thus, ultimately, adaptiveness of habitat preferences probably results from the adaptiveness of multiple phenotypic traits (e.g., physiological tolerance, background matching, behavioral activity patterns) to preferred habitats. In short, much remains to be learned about the adaptive bases of habitat choices and preferences. Advances in understanding adaptiveness of habitat preferences can be provided by delineating the mechanistic bases and phenotypic traits that underlie the costs of using nonpreferred habitats. Such advances can be made most readily by measuring fitness consequences of habitat use by individuals (Martin 1986, Petit and Petit 1996).

\section{ACKNOWLEDGMENTS}

I appreciate comments provided by A. Badyaev, W. J. Etges, R. Hutto, J. Jaenike, P. Martin, B. Maurer, T. B. Smith, and an anonymous reviewer on earlier drafts. I thank C. Olson for help in developing Figure 1. I thank many field assistants for help in collecting the field data. I thank Arizona Game and Fish Agency, Blue Ridge Ranger Station of the Coconino National Forest, and the Apache-Sitgreaves National Forest for their support of this work. This study was supported by grants from the National Science Foundation (BSR-8614598, BSR-9006320, DEB-9407587, DEB-9527318), the BBIRD (Breeding BIology Research and Monitoring Database) program under the Global Change Research Program of the Biological Resources Division, and Arizona Game and Fish Agency.

\section{Literature Cited}

Barker, P. A. 1977. Canyon maple-a colorful mountaineer American Forests 1977:22-25.

Barker, P. A., D. C. Freeman, and K. T. Harper. 1982. Variation in the breeding system of Acer grandidentatum. Forest Science 28:563-572.

Brown, J. L. 1969. Territorial behavior and population regulation: a review and re-evaluation. Wilson Bulletin 81: 293-329.

Cody, M. L., editor. 1985. Habitat selection in birds. Academic Press, New York, New York, USA.

Dhondt, A. A., B. Kempenaers, and F. Adriaensen. 1992. Density-dependent clutch size caused by habitat heterogeneity. Journal of Animal Ecology 61:643-648.

Endler, J. A. 1986. Natural selection in the wild. Princeton University Press, Princeton, New Jersey, USA.

Etges, W. J. 1993. Genetics of host-cactus response and lifehistory evolution among ancestral and derived populations of cactophilic Drosophila mojavensis. Evolution 47:750767.

Fretwell, S. D. 1972. Populations in a seasonal environment. Princeton University Press, Princeton, New Jersey, USA.

Hand, D. J. 1981. Discrimination and classification. John Wiley and Sons, New York, New York, USA.

Hensler, G. L., and J. D. Nichols. 1981. The Mayfield method of estimating nesting success: a model, estimators and simulation results. Wilson Bulletin 93:42-53.

Hines, J. E., and J. R. Sauer. 1989. Program CONTRAST: a general program for the analysis of several survival or recovery rate estimates. U.S. Fish and Wildlife Service Fish and Wildlife Technical Report 24.
Isely, D., and F. J. Peabody. 1984. Robinia (Leguminosae: Papilionidea). Castanea 49:187-202.

Jaenike, J. J., and R. D. Holt. 1991. Genetic variation for habitat preference: evidence and explanations. American Naturalist 137:S67-S90.

Johnson, D. H. 1979. Estimating nest success: the Mayfield method and an alternative. Auk 96:651-661.

Karr, J. R., and K. E. Freemark. 1983. Habitat selection and environmental gradients: dynamics in the "stable" tropics. Ecology 64:1481-1494.

Lande, R., and S. J. Arnold. 1983. The measurement of selection on correlated characters. Evolution 37:1210-1226.

Martin, T. E. 1986. Competition in breeding birds: on the importance of considering processes at the level of the individual. Current Ornithology 4:181-210.

- 1988. On the advantage of being different: nest predation and the coexistence of bird species. Proceedings of the National Academy of Sciences (USA) 85:2196-2199.

1992. Breeding productivity considerations: what are the appropriate habitat features for management? Pages 455-473 in J. M. Hagan and D. W. Johnston, editors. Ecology and conservation of neotropical migrants. Smithsonian Institution Press, Washington, D.C., USA.

- 1993. Nest predation and nest sites: new perspectives on old patterns. BioScience 43:523-532.

_. 1996. Fitness costs of resource overlap among coexisting bird species. Nature 380:338-340.

Martin, T. E., and G. R. Geupel. 1993. Nest-monitoring plots: methods for locating nests and monitoring success. Journal of Field Ornithology 64:507-519.

Martin, T. E., and J. J. Roper. 1988. Nest predation and nest site selection in a western population of the Hermit Thrush. Condor 90:51-57.

Mayfield, H. 1975. Suggestions for calculating nest success. Wilson Bulletin 87:456-466.

Morse, D. H. 1974. Niche breadth as a function of social dominance. American Naturalist 108:818-830.

- 1976. Hostile encounters among spruce-woods warblers (Dendroica, Parulidae). Animal Behavior 24:764771.

Noon, B. R. 1981. The distribution of an avian guild along a temperate elevational gradient: the importance and expression of competition. Ecological Monographs 51:105-124.

Peattie, D. C. 1953. A natural history of western trees. Riverside Press, Cambridge University Press, New York, New York, USA.

Petit, L. J., and D. R. Petit. 1996. Factors governing habitat selection by Prothonotary Warblers: field tests of the Fretwell-Lucas models. Ecological Monographs 66:367-387.

Price, T. D., and P. T. Boag. 1987. Selection in natural populations of birds. Pages 257-287 in F. Cooke and P. A. Buckley, editors. Avian genetics: a population and ecology approach. Academic Press, New York, New York, USA.

Pulliam, H. R. 1988. Sources, sinks, and population regulation. American Naturalist 132:652-661.

Thompson, J. N., W. Wehling, and R. Podolsky. 1990. Evolutionary genetics of host use in swallowtail butterflies. Nature 344:148-150.

Weathers, W. W., and K. A. Sullivan. 1989. Nest attentiveness and egg temperature in the Yellow-eyed Junco. Condor 91:628-633.

Whitham, T. G. 1980. The theory of habitat selection: examined and extended using Pemphigus aphids. American Naturalist 115:449-466.

Williams, B. K. 1983. Some observations on the use of discriminant analysis in ecology. Ecology 64:1283-1291.

Valladares, G., and J. H. Lawton. 1991. Host-plant selection in the holly leaf-miner: does mother know best? Journal of Animal Ecology 60:227-240.

van Horne, B. 1983. Density as a misleading indicator of habitat quality. Journal of Wildlife Management 47:893901 . 